\title{
Capsule Commentary on Murray et al. Antihypertensive Medication and Dementia Risk in Older Adult African-Americans with Hypertension: a Prospective Cohort Study
}

\author{
Lauren E. Cipriano, PhD \\ J Gen Intern Med 33(4):496 \\ DOI: $10.1007 / \mathrm{s} 11606-018-4340-\mathrm{y}$ \\ (c) Society of General Internal Medicine 2018
}

Ivey Business School, Western University, London, ON, Canada.

$\mathrm{M}$ urray and colleagues ${ }^{1}$ present a prospective, observational study on 1236 community-dwelling AfricanAmericans with hypertension and no dementia at baseline with longitudinal follow-up of up to 24 years. In models that did not adjust for the effectiveness of hypertension control, being prescribed any hypertension medication was protective against dementia, but this finding was not statistically significant (HR $=0.65,95 \% \mathrm{CI} 0.38-1.12$ ). An analysis incorporating the effectiveness of hypertension control indicated that optimal blood pressure control $(<140 \mathrm{mmHg}$ systolic and $<90 \mathrm{mmHg}$ diastolic) significantly decreases the risk of dementia (HR = $0.46,95 \%$ CI $0.25-0.82$ ). This work adds to a growing and compelling literature indicating that effective control of hypertension prevents cognitive impairment and dementia.

This study is unique in focusing on African-Americans, who are under-represented in other prospective cohort studies. While hypertension rates are concerningly high in all groups, African-Americans are nearly 50\% more likely to be affected with an (unadjusted) relative risk of approximately 1.46 (95\%CI $1.3-1.6) .^{2}$ Recent NHANES analysis indicated that although African-Americans are as likely to be prescribed antihypertensives $(70.8 \%$ [95\% CI 68.6-73.0\%] vs. $73.9 \%$ [95\%CI 71.6-76.2\%]), they are less likely than white Americans to achieve hypertension control (OR 0.73, 95\% CI 0.63-0.83). ${ }^{3}$ For all racial groups, blood pressure control (by JNC7 standards) is low: $42.9,36.9$, and $31.2 \%$ for white, African-Americans, and Hispanic-Americans, respectively, ${ }^{3}$ and these numbers have barely improved over the last decade. ${ }^{2}$

Patient health can be improved through hypertension prevention, as well as improvements in diagnosis rates, treatment initiation, and treatment monitoring to ensure treatment adherence and disease control. Treatment of hypertension in indi- viduals over 45 years of age for the prevention of cardiovascular events is cost-saving in men and highly cost-effective in women. ${ }^{4}$ Furthermore, patient-oriented education programs aimed at addressing health system, patient, and provider barriers have demonstrated both effectiveness (average of $9 \mathrm{mmHg}$ greater reduction in systolic blood pressure) and cost effectiveness. ${ }^{5}$ Incorporating the patient, caregiver, and societal benefits of dementia prevention into future cost effectiveness studies of hypertension diagnosis and management will improve the already overwhelming health economic evidence for the prevention, diagnosis, and management of hypertension.

Corresponding Author: Lauren E. Cipriano, PhD; Ivey Business School, Western University, London, ON, Canada (e-mail: lcipriano@ivey.uwo.ca).

\section{Compliance with Ethical Standards:}

Conflict of Interest: The author has no conflicts of interest with this article.

\section{REFERENCES}

1. Murray MD, Hendrie HC, Lane KA, Zheng M, Ambuehl R, Li S, Unverzagt FW, Callahan CM, Gao S. Antihypertensive medication and dementia risk in older adult african americans with hypertension: a prospective cohort study. J Gen Intern Med. https://doi.org/10.1007/ s11606-017-4281-x.

2. Cutler JA, Sorlie PD, Wolz M, Thom T, Fields LE, Roccella EJ. Trends in hypertension prevalence, awareness, treatment, and control rates in United States adults between 1988-1994 and 1999-2004. Hypertension. 2008; 52(5): 818-27.

3. Gu A, Yue Y, Desai RP, Argulian E. Racial and ethnic differences in antihypertensive medication use and blood pressure control among us adults with hypertension: The National Health and Nutrition Examination Survey, 2003 to 2012. Circ Cardiovasc Qual Outcomes. 2017;10(1): e003166.

4. Moran AE, Odden MC, Thanataveerat A, Tzong KY, Rasmussen PW, Guzman D, Williams L, Bibbins-Domingo K, Coxson PG, Goldman L. Cost-effectiveness of hypertension therapy according to 2014 guidelines. N Engl J Med. 2015; 372(5): 447-455.

5. Hong JC, Padula WV, Hollin IL, Hussain T, Dietz KB, Halbert JP, Marsteller JA, Cooper LA. Care management to reduce disparities and control hypertension in primary care: a cost-effectiveness analysis. Med Care. 2018; 56(2): 179-185. 